\title{
FarmBid - A Bidding E-commerce Platform to Provide Fresh Produces from Farmers to Customers
}

\section{Aloysius Chiong Zhen Quan' ${ }^{1}$, Khairunnisa binti Sufian ${ }^{2}$, Ng Sing Woei $^{1}$, Lai Li Ying ${ }^{1 *}$ and Amanda Ling Tzi Yun ${ }^{1}$}

${ }^{1}$ Faculty of Computer Science and Technology Information, Universiti Malaysia of Sarawak, Malaysia

${ }^{2}$ Faculty of Economics and Business, Universiti Malaysia of Sarawak, Malaysia

*Corresponding Author: Lai Li Ying, Faculty of Computer Science and Technology

Information, Universiti Malaysia of Sarawak, Malaysia.
Received: September 14, 2021

Published: September 24, 2021

(C) All rights are reserved by Lai Li Ying., et al.

\section{Abstract}

Contract farming derived benefits such as improved agricultural production and increased incomes for contract farmers, allowing better access to services and resources provided new opportunities to participate in markets. However, it has been criticised for the uneven bargaining power that may lead to the exploitation of farmers by large agribusiness firms. FAMA describes contract farming as a potential strategy that provides farmers and producers many benefits. Free agriculture markets in Malaysia often face inflexible elements which allow direct intervene from governments. Besides, the existence of middlemen in the supply chain further pressures the farmers, forcing them to rely on middlemen to sell their products. FarmBid, a bidding integrated e-commerce platform, is a solution to increase the farmers' bargaining power so that it can increase their income.

Fieldwork is performed on 30 respondents, consisting of 2 main segments, buyers (16 respondents) and sellers (14 respondents). Results show that most buyers prefer to have a direct purchase from farmers and from mobile application too. The addition of delivery service will be a better push for buyer to make a purchase. On the other hand, sellers claimed to have more than $15 \mathrm{~kg}$ production daily which makes a good production rate for the community. Similarly to buyers, a standardized delivery service is a great boost for sellers' business.

It was observed that direct negotiation from farmers to customers and standardized delivery service are some of the good features which FarmBid should take into consideration. Hence, the quality of farmers' life can be improved with the introduction of FarmBid by increasing their income.

Keywords: Bidding; E-commerce; Agriculture; Mobile Application; Middlemen; Supply Chain

\section{Abbreviations}

SDG: Sustainable Development Goals; FAMA: Federal Agriculture Marketing Authority.

\section{Introduction}

According to the FAMA, contract farming has potentially provided to farmers and producers, aside from guaranteed markets, access to inputs, loans and credit, extension and technical advice, updated technology, and management systems. It was also observed that in the post-contract farming programme, most of the farmers marketed their entire produce through FAMA. This indicated the importance of FAMA as a mechanism or platform to help small and medium-scale farmers to improve their marketing strategy and sell their produce [5].

Contract cultivation, on the other hand, has been criticised. Uneven bargaining power may lead to the exploitation of farmers by 
large agribusiness firms, who may breach the contractual terms at the expense of smallholders due to unequal market power. On the other hand, Freguin-Gresh., et al. suggested that contract farming derived benefits such as improved agricultural production and increased incomes for contract farmers, allowing better access to services and resources, and provided new opportunities to participate in markets. However, they concluded that contract farming did not have an effective way of reducing poverty or a systemic mechanism for improving rural livelihoods on its own [4].

According to Malaysia's Ninth Malaysia Plan (2006-2010), the agricultural sector will be revitalised to become the third engine of growth after the services and manufacturing sectors. The fact that a new perception that agricultural growth plays a major role in overall growth and poverty reduction through the supply chain and international trade network linkages to manufacturing and services, the agricultural sector is once again on the government's agenda. Hence, the position of agriculture as a vital engine of growth includes not only the development of oil palm, rubber, livestock, and fisheries but also the economic activities in their entire supply chains, which can be described as "from seed to shelf".

Even though the agricultural markets in Malaysia are structured as free markets, there exist some inflexible elements, such as government subsidies and support programmes, which allow direct intervene from the government in the market system, prices, and resource allocations. It is visible in Malaysia's Department of Agriculture's direct involvement in assisting farmers in developing agricultural property. Nonetheless, Malaysian farmers received significant government assistance due to unforeseen circumstances; difficulty in cultivating their agricultural land, particularly from a financial standpoint. Agricultural projects in Malaysia are structured as smallholdings owned by rural families and households. The majority of these small-scale agricultural have little ability to raise income above the families' subsistence needs. This reflects the rural sector's limited production capability, which is reliant on the immediate needs of the household. Furthermore, most of the products are perishable. The in-depth rural areas also limiting the farmers from accessing any society-friendly policies.

Sarawak, the largest state of Malaysia, with an area of 124450 $\mathrm{km}$, is almost equal to that of Peninsular Malaysia [6]. It houses over 120000 farm families, which makes it one of the largest farm communities in Malaysia. There are many districts and villages that cultivate crops on a small scale. Studies show that, despite support from the state government in the form of subsidies and other forms of assistance, rural communities have continued to face challenges in marketing their agricultural produce. Agricultural commodity sales are also influenced by vicious market price fluctuation (e.g., rubber and pepper), making them susceptible to market shocks. Their insecurity is exacerbated by the internal market, which is caused by middlemen's coercive practices. Since most of Sarawak's rural areas have restricted access to external markets, the existence of middlemen throughout the whole supply chain allows them to take advantage of the internal market price. Rural residents often rely on middlemen to exchange their produce, albeit at reduced rates, due to limited access to markets. Many rural areas lag in terms of growth and infrastructure, which influences their quality of living and the livelihood strategies they employ.

In conclusion, Sarawak's economic output varies from that of other Southeast Asian economies (e.g., Thailand, Vietnam, and Indonesia), as well as that of rural areas in Peninsular Malaysia. Despite having similar socioeconomic and geographical characteristics: low population, poor infrastructure, and rural position, Sarawak has undergone a slower pace of de-agrarianisation than the rest of the states in Malaysia. Coupled with its low population density, or scattered population has not resulted in the same level of strain as other Southeast Asian countries.

FarmBid, a bidding e-commerce platform to provide fresh produces from farmers to customers, in a form of a mobile application. The existence of FarmBid is to raise the awareness of the exploitation of middlemen in the agriculture sector through purposely overestimated deduction rates to secure their profit margins, leaving farmers with inadequate income. Several services are provided:

- $\quad$ To increase the farmers' financial power by providing a bidding integrated e-commerce platform to increase their income.

- To improve the accessibility of the market as well as accurate and latest market information by providing a transparent market information platform to the farmers and endconsumers.

- $\quad$ To produce agriculture products with lower selling prices by simplifying the long and repetitive supply chain to enable end-consumer to buy products at a more reasonable price. 
In Malaysia, our solution is said to be the first to provide such a platform to farmers and consumers. Although there are several e-commerce platforms exist such as Shopee and Lazada, but none of them focuses solely on the agricultural sector. However, here in Sarawak, there are 2 alternatives that provided service directly to the agriculture sector, namely Timogah and Agrobazaar, without the bidding concept.

- Timogah: An e-marketplace whereby customers could order fresh and quality agriculture products, including local crops and jungle produce, complete with delivery. According to the founder, Mr Heineken, said that they are also known as an agriculture e-hailing platform [7].

- Agrobazaar: A project initiated by a government agency, named Federal Agricultural Marketing Authority that focuses on the farmers in the rural areas and helps them to sell their products online [2].

The very idea of FarmBid is redefined from the "Buyee" Japanese Proxy Service. "Buyee" focuses on a variety of products such as figure toys, fashion, turntables, and others provided to international customers [1]. Similarly yet differently, we are trying to expand the bidding concept to the agricultural sector which involved vegetables and fruits. The concept is built on top of mobile application architecture because according to Digital Influence Lab, the mobile penetration rate in the Malaysian community (65\%) is far greater than tablets and laptops [3]. By aligning ourselves with the United Nation's SDG:

- $\quad$ SDG 1: No Poverty;

- $\quad$ SDG 4: Quality Education; and

- SDG 8: Decent Work with Economic Growth,

We believe that the farmers could expand their business beyond the traditional architecture of the local market, reaching the height of being capable to live a quality life.

\section{Materials and Methods}

The target group are the farmers and buyers with the total sample size of 30 subjects. Subjects staying or having business in Kuching and Asajaya were prioritised. To generate ideas on the agriculture mobile bidding platform and obtain farmers and buy- ers' awareness on the exploitation of middleman influences in the agriculture sector, survey forms and interview methods are implemented to collect data. Google form was used as a tool to create the survey forms and distributed using social media platforms.

The questionnaires and interview questions were designed using the psychographic and demographic characteristics. Opinion, attitudes, and beliefs of the subjects were collected to analyse their thoughts on the middleman's influences on their business and sustainability. Their opinions on willingness to accept changes in their business were also collected. As for the demographic data, we focus on the two areas mentioned as these two areas have higher market flow rate on products. Thus, as a result, 2 different sets of questions are dedicated to different segments of respondents.

\section{Results and Discussion}

The study was conducted on 30 participants living in Sarawak. The purpose of the study is to conduct a fieldwork on the participants' perspective on FarmBid. 2 segments of participants are categorized, namely buyers (16 respondents) and sellers (14 respondents). The data collected illustrated as shown in the following results.

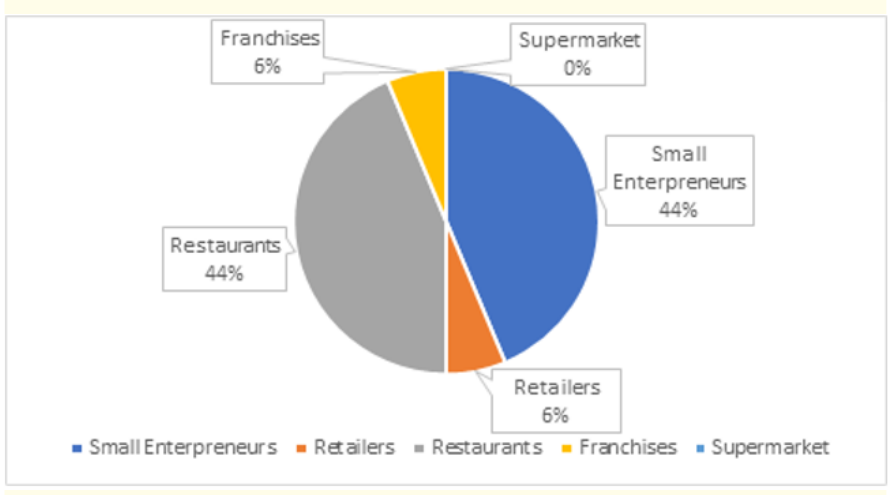

Figure 1: Type of business model.

Figure 1 depicts that $44 \%$ of the respondents had the business model type of restaurant, $44 \%$ are small entrepreneurs, $6 \%$ are franchisees, and $6 \%$ are retailers. All 16 respondents are from Kuching Division, with $37.5 \%$ of the respondents are from Kuching district. 


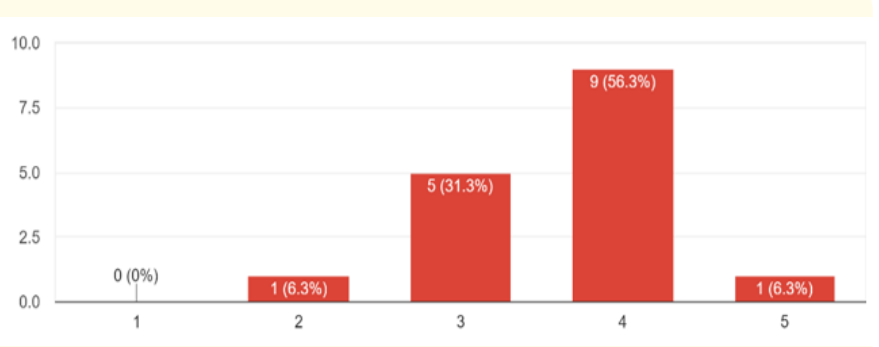

Figure 2: Respondents on direct purchase from farmers.

Figure 2 shows that 10 respondents agree that they prefer to buy agriculture products directly from farmers instead of intermediary, 5 respondents answered neutral, and only 1 respondent answers otherwise.

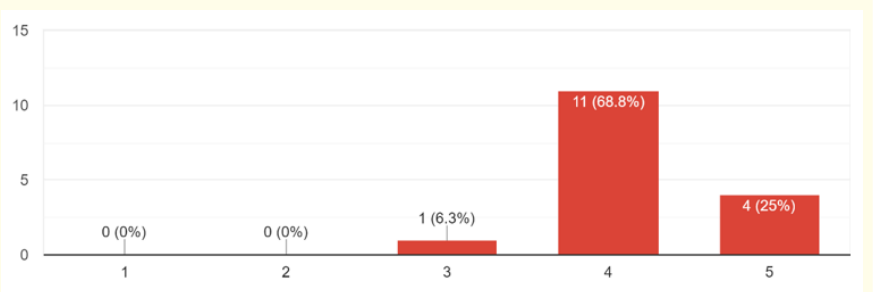

Figure 3: Respondents on interest of purchasing agriculture products from mobile app.

As shown in Figure 3, 15 respondents are highly interested in using and buying agricultural products through the mobile app, and only 1 respondent is neutral for this matter.

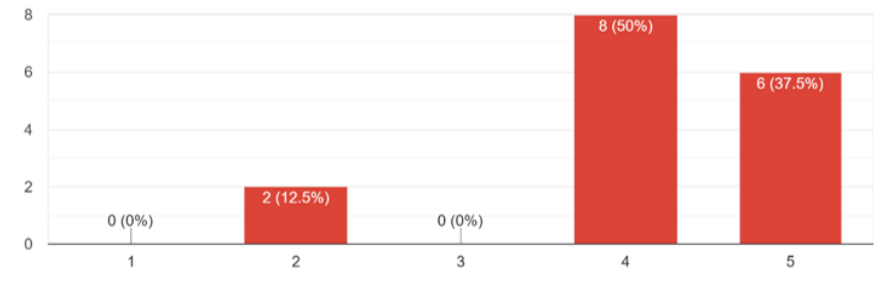

Figure 4: Respondents on the availability of delivery service.
Figure 4 illustrates that 14 respondents agreed that the delivery service is a key service in FarmBid, however 2 respondents disagreed on that.

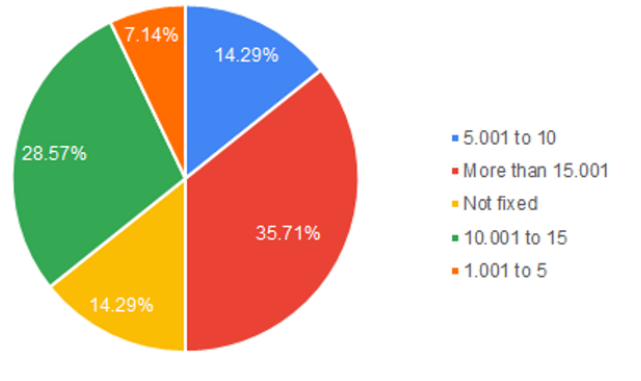

Figure 5: Respondents on daily production in kg.

According to figure 5, 35.7\% of farmers claimed that their crops production weight is more than $15 \mathrm{~kg}$, while $28.6 \%$ of farmers mentioned their production weight is between $10 \mathrm{~kg}$ to $15 \mathrm{~kg}$. Besides, $14.3 \%$ of farmers do not have fixed production weight, another $14.3 \%$ of them have production weight between $5 \mathrm{~kg}$ to $10 \mathrm{~kg}$ and $7.1 \%$ have production of crops between $1 \mathrm{~kg}$ to $5 \mathrm{~kg}$.

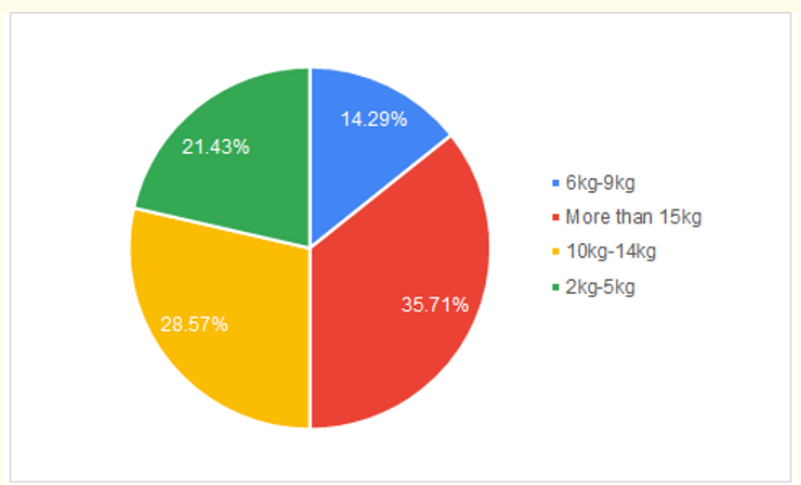

Figure 6: Respondents on daily sales in $\mathrm{kg}$.

According to figure 6, 35.7\% of farmers normally sell more than $15 \mathrm{~kg}$ of crops per day, while the second $28.6 \%$ can sell $10 \mathrm{~kg}$ to $14 \mathrm{~kg}$ 
of crops per day. $21.4 \%$ of farmers can sell $2 \mathrm{~kg}$ to $5 \mathrm{~kg}$, and another $14.3 \%$ can only sell $6 \mathrm{~kg}$ to $9 \mathrm{~kg}$ a day.

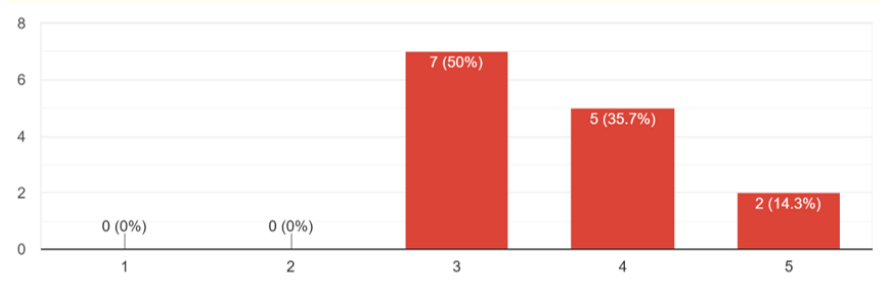

Figure 7: Respondents of largest production capability for auction.

Figure 7 illustrates that $50 \%$ of the respondents preferred to sell their products at their current fullest during every auction and another $50 \%$ of the respondents remained neutral. $50 \%$ of the respondents prefer to sell all their products in one go through an auction to secure sales and business at the same time. As for the other $50 \%$ of respondents, they are staying neutral because they want to have some stock in hand that can be sold separately rather than clearing the storage in one go. Another reason is that the respondents ( 9 out of 14 respondents) are unfamiliar with bidding concepts.

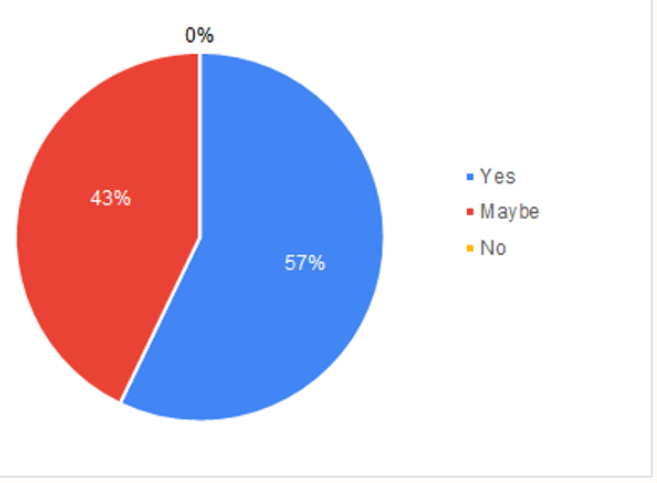

Figure 8: Respondents on the preference of standardized delivery service.

As illustrated in figure 8, 57.1\% of respondents preferred FarmBid to have a standardized delivery service while $42.9 \%$ answered maybe. As a result, most of them believe that a standardized delivery service is desirable.

\section{Conclusion}

In conclusion, the results showed that most of the sellers produce and sell most of the crops daily. As a result, they hope Farmbid could support them in selling their produce at its peak during each auction. A standardized delivery service would be ideal for them since it would make outsourcing goods much easier and more convenient. Meanwhile, the buyers with restaurants and small entrepreneurs as the business models wish to acquire agricultural products directly from farmers. The buyers also indicated they have a high interest on a standardized delivery service.

\section{Bibliography}

1. Buyee. "Buyee” japanese proxy service. (2021).

2. dayakdaily. FAMA negeri sarawak lancar agroxpress (2020).

3. digitalinfluencelab. Malaysia digital marketing statistics 2020 (2021).

4. Freguin-Gresh., et al. "Demythifying contract farming evidence from rural south africa”. Agrekon: Agricultural Economics Research, Policy and Practice in Southern Africa 51.3 (2012): 2451.

5. Kaur Bisant., et al. "The impact of public-assisted contract farming programmes in Malaysia". Journal of Agribusiness Marketing 7 (2015): 1-15.

6. Sarawak Government. The Greography of Sarawak (2021).

7. Ten Marilyn. Helping small rural farmers via e-marketplace (2020).

\section{Volume 4 Issue 10 October 2021 \\ (C) All rights are reserved by Lai Li Ying., et al.}

